\title{
Design and manufacture of safflower petal harvester machine
}

\author{
Siavash Azimia ${ }^{a}$, Gholamreza Chegini and Mohamad Hosein Kianmehr \\ Department of Agrotechnology, College of Abuoreihan, University of Tehran, Tehran, Iran
}

Received 18 May 2012, Accepted 21 September 2012

\begin{abstract}
Safflower is an oil-seed crop with high quality oil that is used for producing healthy foods and painting colors. This crop has valuable petals which have a lot of uses in medicine, production of food colors and dyes for coloring fabrics, but such problem as dispersion of flowers, thorns of crops that hurt worker's hands also lack of a suitable harvesting machine have enforced farmers to harvest petals by hand that is a hard work and non-economic. In this study a prototype machine was designed and constructed. This machine includes an engine, a radial fan with BI blades, a snout, a diffuser to separate petals from airflow and a store; all parts are assembled on a trolley to move easily in farm. This machine picks safflower petals out and intakes through snout by the fan suction power. Petals go to diffuser where they are separated from airflow then fall to the store. Velocity of airflow in the snout was determined by a fan test duct in order to design diffuser. At last three farms were harvested by this machine for economic analysis. Results show $657 \%$ increasing in amount of harvested petals by harvester machine in comparison with hand harvesting.
\end{abstract}

Key words: Harvester / fan / suction / safflower / petal

\section{Introduction}

Safflower (Carthamus tinctorius L.) belongs to the Asteraceae family. It ranks eighth among the major oilseed crop grown worldwide. Safflower is known from antiquity in eastern Mediterranean, India, Egypt, Iran and other Asian countries and North Africa. It is adapted to relatively low rainfall areas receiving winter and spring rainfall with a dry atmosphere during flowering and maturation. It shows considerable resistance to drought and wind $[1-4]$.

This crop has been cultivated for a long time as the source of red and yellow pigments which are constituents of safflower petals and are used chiefly in coloring food. The dye is called safflower Carmin. Most production is now just for the seed oil (USA), but in Bengal and France it is still grown for the dye [2].

Safflower petals are common aromatic and medicinal herbs with centuries of use [5]. Flos carthami, the dried flower petal of safflower is an important crude drug in traditional Chinese medicine for promoting blood circulation and removing obstruction in the channels [6].

The dry weight of petal per plant ranged from 0.2 to $0.8 \mathrm{~g}$ with an average of $0.48 \mathrm{~g}$ per plant. At the rate of 200000 plants per ha, $96 \mathrm{~kg}$ of plants would be the expected yield [1].

${ }^{a}$ Corresponding author: Sia.azimi@ut.ac.ir

\section{Nomenclature}

\begin{tabular}{|ll|}
\hline$A_{1}$ & area of snout $\left(\mathrm{m}^{2}\right)$ \\
$A_{2}$ & area of diffuser $\left(\mathrm{m}^{2}\right)$ \\
$N_{\mathrm{s}}$ & specific speed \\
$V_{1}$ & airflow velocity in first duct $\left(\mathrm{m}_{\mathrm{s}} \mathrm{s}^{-1}\right)$ \\
$V_{2}$ & airflow velocity in second duct $\left(\mathrm{m}_{\mathrm{s}} \mathrm{s}^{-1}\right)$ \\
$D$ & duct diameter $(\mathrm{m})$ \\
$d$ & fan diameter $(\mathrm{m})$ \\
$N$ & fan speed $(\mathrm{rpm})$ \\
$P$ & static pressure $(\mathrm{Pa})$ \\
$Q$ & airflow rate $\left(\mathrm{m}^{3} \cdot \mathrm{s}^{-1}\right)$ \\
$q$ & dynamic pressure $(\mathrm{Pa})$ \\
$V$ & fluid velocity $\left(\mathrm{m} \cdot \mathrm{s}^{-1}\right)$ \\
$W$ & fan width $(\mathrm{m})$ \\
$\rho$ & fluid density $\left(\mathrm{kg} \cdot \mathrm{m}^{-3}\right)$ \\
$\Psi_{0}$ & fan coefficient \\
$\phi$ & fan coefficient \\
rpm & revolutions per minute \\
\hline
\end{tabular}

Besides mentioned uses for safflower petals, there isn't any suitable machine for harvesting them. Enhance farmers have to harvest petals manually that is slow, expensive and time consuming with high losses. Also worker's hands are injured in contact with crop thrones.

All of these problems make petals harvesting noneconomical, sometimes. So it is decided to design and manufacture a prototype machine for harvesting safflower 
Table 1. Flow and pressure coefficients for various impeller types.

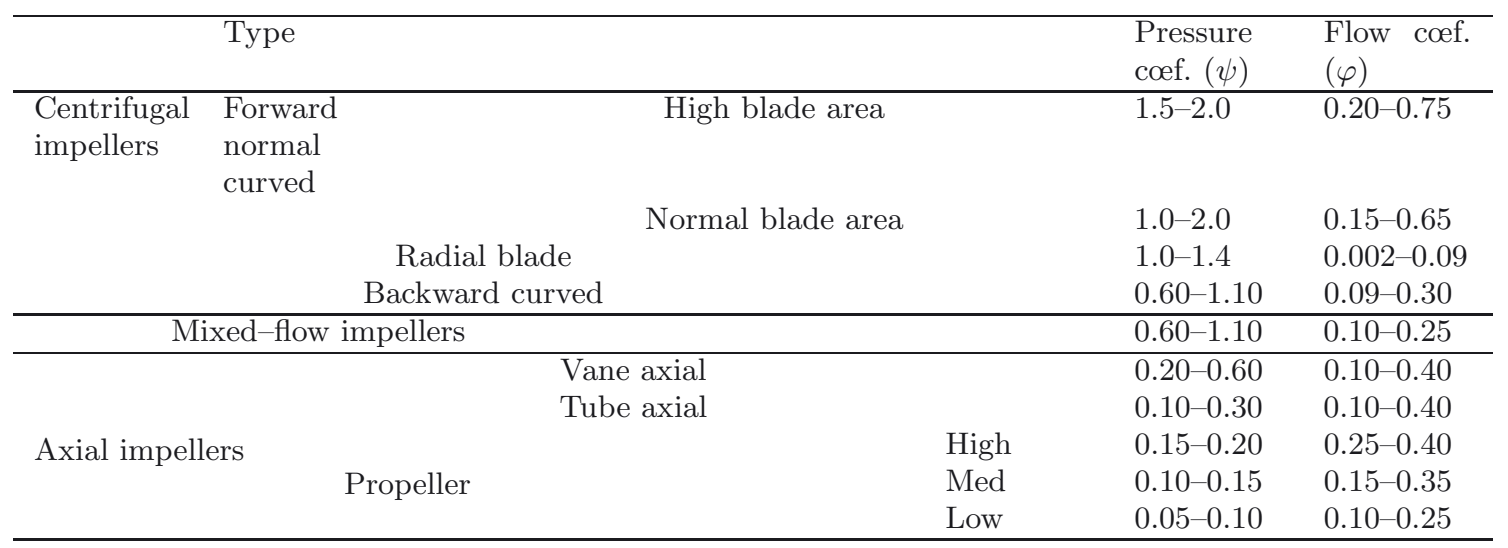

petals. To find a suitable way for harvesting safflower petals, some similar projects were studied which in following are come.

An organization in Iran named, Iran cotton union, has made a machine which harvests cottons by suction force and gathers in a reservoir. It has some snouts which operator places on cottons then machine sucks them off [7].

A vacuum system has been designed for harvesting rangeland and grass seeds from the soil surface or the plant canopy including vacuum harvester head, thresher and cleaner units in Tarbiat Modares University in $\operatorname{Iran}[8]$.

An organization in India named NARI (Nimbkar Agricultural Research Institute) has made two types of safflower petal collectors. One of them works by battery energy and is placed on worker's shoulder during harvesting. Another works by a petrol-powered engine and is carried on a trolley. In both, petals are taken off and gathered by suction force and are separated from airflow by cyclone [9].

\section{Materials and methods}

\subsection{Philosophy of design}

A number of points were considered during the design such as cost of construction, enough suction power, easy moving of machine in farm, separating petals from airflow completely. Also the ability of replacement and fixing of damaged or failure components were considered.

\subsection{Prototype machine description}

The machine comprises five major components assembled together: engine, fan, diffuser, store, and snout.

- Engine: A two stroke internal combustion engine turns the fan and produces suction power. This is a petrol-powered engine with $0.7 \mathrm{~kW}$ power and $5500 \mathrm{rpm}$ as maximum rotational speed. Crankshaft is connected to the fan shaft by bolts.
- Fan: A radial fan with 12 steep BI blades was used for producing suction power. This fan has $0.3 \mathrm{~m}$ diameter and $0.06 \mathrm{~m}$ width.

Equation (1) was used to determine static pressure [8]

$$
P=249.08 \Psi_{0}\left(\frac{N \times D \times 39.37}{1.53 \times 10^{4}}\right)^{2}
$$

where:

$P=$ static pressure $(\mathrm{Pa})$

$D=$ fan diameter $(\mathrm{m})$

$N=$ fan speed (rpm)

$\Psi_{0}=$ fan coefficient.

Fan diameter was $0.3 \mathrm{~m}$, fan speed was $4400 \mathrm{rpm}$ (chosen speed as optimum speed of the fan) and coefficient $\Psi_{0}$ was 1.1 for radial fans which come in Table 1. Typical values for flow and pressure coefficients, for all major impeller types, are listed in Table 1 [10]. So with these parameters and calculating (Eq. (1)) static pressure of fan was determined which was $3161 \mathrm{~Pa}$.

Equation (2) was used to determine airflow rate of fan $[10]$ :

$$
Q=0.163 \varphi \cdot \text { W.N.D }{ }^{2}
$$

where:

$Q=$ airflow rate $\left(\mathrm{m}^{3} \cdot \mathrm{s}^{-1}\right)$

$W=$ fan width $(\mathrm{m})$

$N=$ fan speed (rpm)

$D=$ fan diameter $(\mathrm{m})$

$\phi=$ fan coefficient.

Fan width was $0.06 \mathrm{~m}$, fan speed was $4400 \mathrm{rpm}$, fan diameter was $0.3 \mathrm{~m}$ and $\phi$ for radial fans was 0.09 (come in Tab. 1). So with these parameters and calculating (Eq. (2)) airflow rate was determined which was $0.348 \mathrm{~m}^{3} \cdot \mathrm{s}^{-1}$.

Equation (3) was used to determine specific speed of fan $[10]$ :

$$
N_{s}=\frac{N \times Q^{1 / 2}}{P^{3 / 4}}
$$

where:

$N_{s}=$ specific speed

$N=$ fan speed (rpm) 


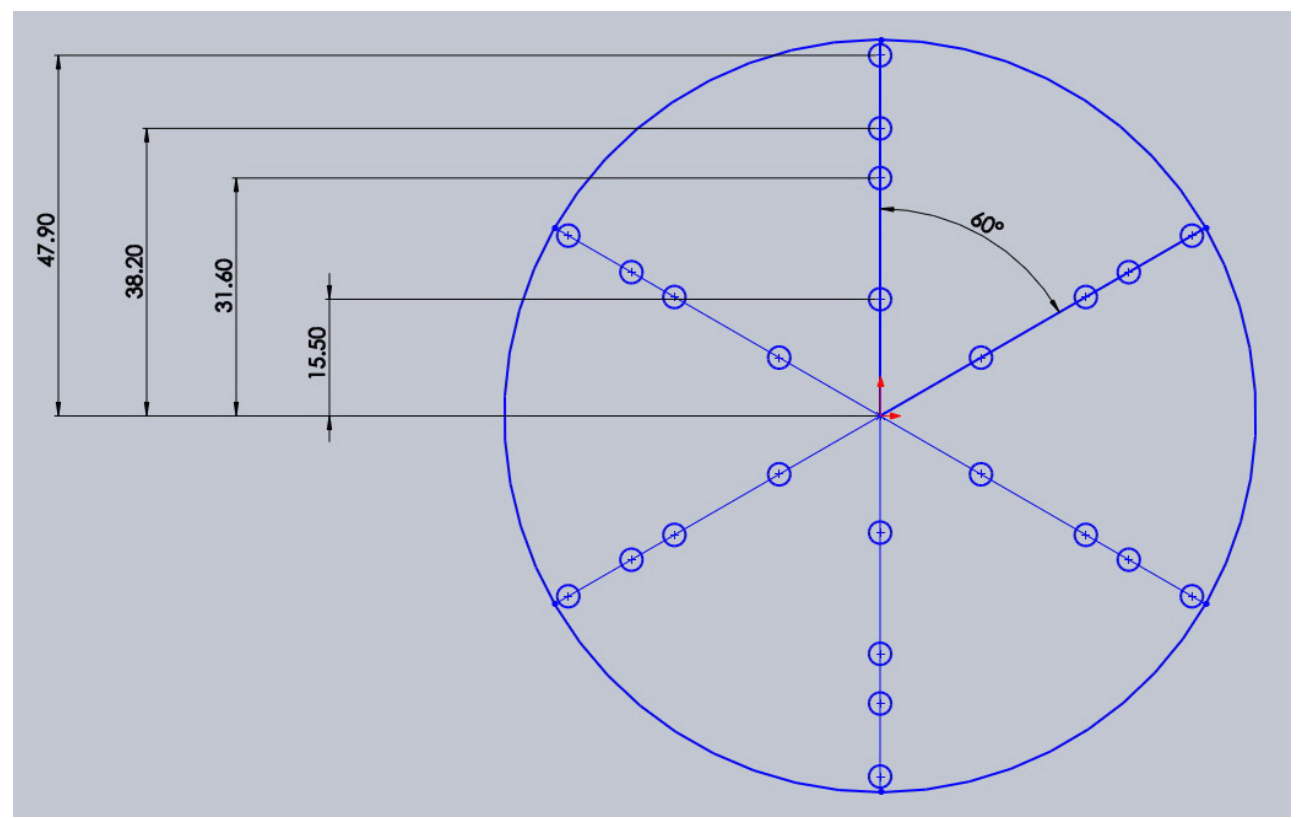

Fig. 1. Traverse points in a round duct per AMCA.

$Q=$ airflow rate $\left(\mathrm{m}^{3} \cdot \mathrm{s}^{-1}\right)$

$P=$ static pressure $(\mathrm{Pa})$.

With calculating (Eq. (3)) specific speed of fan was determined.

Rotational speed of our fan was $4400 \mathrm{rpm}$ and according (Eq. (1)) static pressure was $3161 \mathrm{~Pa}$ and according (Eq. (2)) airflow rate was $0.348 \mathrm{~m}^{3} \cdot \mathrm{s}^{-1}$. So the specific speed became 6.157 .

Snout: we used a flexible snout with $0.03 \mathrm{~m}$ diameter and $2 \mathrm{~m}$ length which is connected to diffuser. Snout loosens the petals and sucks them to diffuser.

The speed of airflow in a duct with $3 \mathrm{~cm}$ diameter was determined by an inlet test duct according AMCA (Air Movement and Control Association) test code.

The technical properties of the duct were: diameter of duct was $0.1 \mathrm{~m}$ and its the length was $1.05 \mathrm{~m}$, orifice diameter was $0.03 \mathrm{~m}$, the distance between pitot tube to fan inlet was $0.02 \mathrm{~m}$, the distance between straightener and duct inlet was $0.15 \mathrm{~m}$ and the its length was $0.45 \mathrm{~m}$.

The dynamic pressure was determined by Pitot tube in 3 orifices and in each orifice at 8 points according "Figure 1" [11]. $0.1 \mathrm{~m}$.

$D$ is the diameter of the duct which for our duct was

The inlet test duct is shown in Figure 2.

The determined average dynamic pressure was $388.57 \mathrm{~Pa}$. Equation (4) was used to determine airflow velocity [12]:

$$
V=\sqrt{\frac{2 q}{\rho}}
$$

where:

$V=$ fluid velocity $\left(\mathrm{m} . \mathrm{s}^{-1}\right)$

$q=$ dynamic pressure $(\mathrm{Pa})$

$\rho=$ fluid density $\left(\mathrm{kg} \cdot \mathrm{m}^{-3}\right)$.

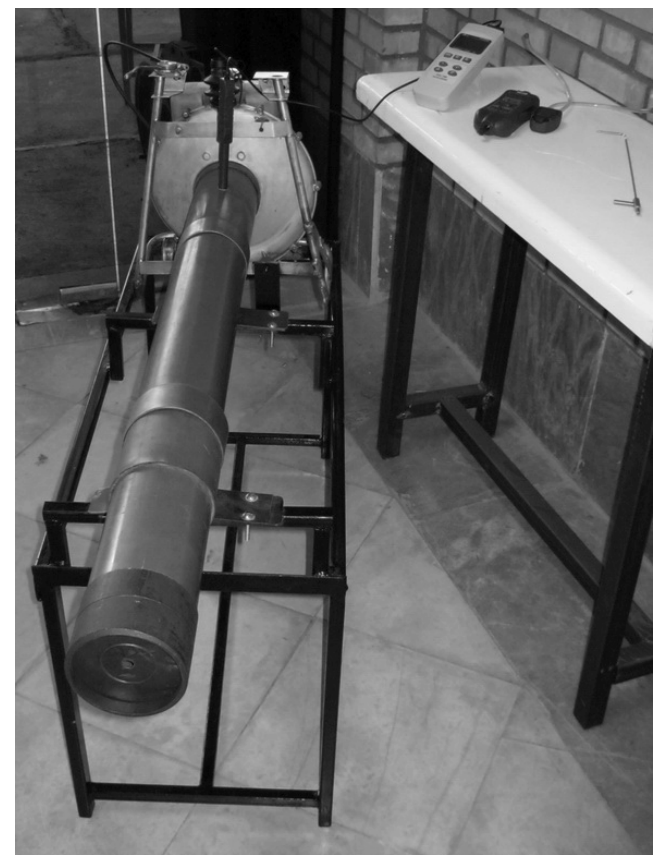

Fig. 2. Inlet duct setup per AMCA.

Test conditions were: relative humidity: $20.9 \%$ and dry temperature inside the duct $28^{\circ} \mathrm{C}$, by psychrometric chart air density was determined $1.19 \mathrm{~kg} \cdot \mathrm{m}^{-3}$.

With calculating (Eq. (4)) airflow velocity was $25.55 \mathrm{~m} . \mathrm{s}^{-1}$.

Diffuser: A space between fan and store that decreases dynamic pressure and airflow velocity subsequently by increasing the area and separates petals from airflow and sends them to store by them weight factor. According to studies the least amount of terminal velocity of safflower petals which was $2.8 \mathrm{~m} . \mathrm{s}^{-1}$ in moisture 


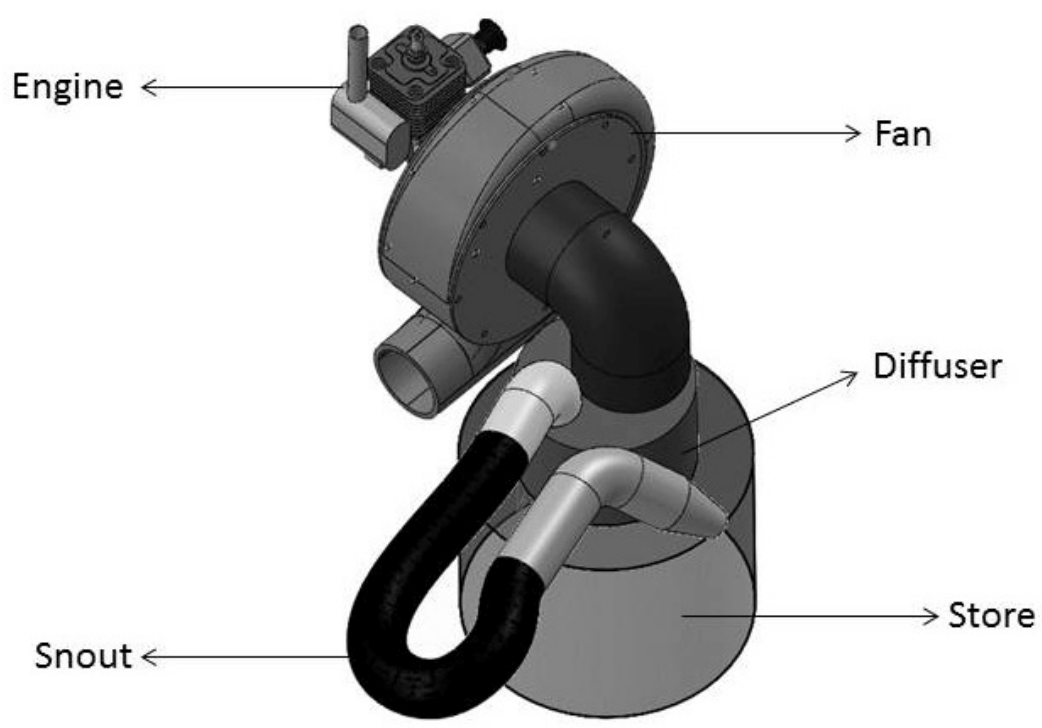

Fig. 3. Safflower petal harvester machine.

Table 2. Economic analysis.

\begin{tabular}{cccc}
\hline & Item & Harvester machine & Hand collection \\
\hline 1 & Cost of machine $(\$)$ & 183 & - \\
2 & Labor cost $\left(\$\right.$. day $\left.^{-1}\right)$ & 30 & 30 \\
3 & Petal collection $\left({\left.\mathrm{kg} . \mathrm{day}^{-1}\right)}^{-1}\right)$ & 2.3 & 0.35 \\
4 & Petal collection $\left(\mathrm{m}^{2} . \mathrm{day}^{-1}\right)$ & 328 & 49 \\
5 & Fuel charges $\left(\$\right.$. day $\left.^{-1}\right)$ & $11(20 \mathrm{Lit})$ & - \\
\hline
\end{tabular}

content of $40 \%$, so $2 \mathrm{~m} . \mathrm{s}^{-1}$ was chosen as airflow velocity in diffuser to separate petals from airflow completely and according Equation (5) its area was determined [12]:

$$
A_{1} \times V_{1}=A_{2} \times V_{2}
$$

where:

$A_{1}=$ area of snout $\left(\mathrm{m}^{2}\right)$

$A_{2}=$ area of diffuser $\left(\mathrm{m}^{2}\right)$

$V_{1}=$ airflow velocity in snout $\left(\mathrm{m} . \mathrm{s}^{-1}\right)$

$V_{2}=$ airflow velocity in diffuser $\left(\mathrm{m} . \mathrm{s}^{-1}\right)$.

With calculating (Eq. (5)) the area of diffuser was $0.902 \mathrm{~m}^{2}$ and because of its cylinder shape, its radius would be $0.536 \mathrm{~m}$.

Store: three points were considered for designing of store, optimum capacity, lack of air leakage and easy discharging. The capacity of store was determined 4 liters according bulk density of petals and the performance of machine in the farm. Also there is a door in bottom of store for discharging when it becomes full. The type of this door is sliding for the least amount of air leakage.

The schematic of machine is shown in Figure 3.

\section{Results and discussion}

4 tests were done with difference times of harvesting for determining ability of machine to harvest petals in different moisture contents. The moisture contents were determined in $70 \%, 60 \%, 50 \%$ and $40 \%$ that machine could harvest all petals in any stage completely although done tests for studding effect of moisture content on required harvest force was significant at $1 \%$.

Some factors were determined as an economic analysis which is shown in Table 2.

\section{Suggestions}

For protecting environment it is better to use hybrid engines instead of petrol-powered engine. Also by using power of tractor engine and more snouts the speed of harvesting could be increased.

\section{References}

[1] C.V.S. Srinivas, B. Praveena, G. Nagaraj, Safflower petals: A source of gamma linolenic acid, Plant Foods for Human Nutrition 54 (1999) 89-92

[2] D.S. Hill, Pests of crops in warmer climates and their control. Springer, ISBN: 978-1-4020-6737-2, 2008

[3] L.D. Sangam, D.U. Hari, M.H. Dattatray, Development of core collection using geographic information and morphological descriptors in safflower (Carthamus tinctorius L.) germplasm, Genetic Resources and Crop Evolution: 2003, pp. $821-830$ 
[4] S.K. Yau, Winter versus spring sowing of rain-fed safflower in a semi-arid, high-elevation Mediterranean environment, Europ. J. Agronomy 26 (2007) 249-256

[5] S. Kaya, T. Kahyaoglu, Moisture sorption and thermodynamic properties of safflower petals and tarragon, J. Food Eng. 78 (2007) 413-421

[6] Z. Zhang, M. Guo, J. Zhang, Identification of AFLP fragments linked to hydroxysafflor yellow a in flos Carthami and conversion to a SCAR marker for rapid selection, Springer Science+Business Media, B.V, 23:229-237, 2008

[7] www .unicot.org/N.html

[8] M.H. Aghkhani, S. Minaee, M.K. Araghi, Design, fabrication and Investigation of a vacuum combine for harvest rangeland seeds, Iranian J. Range and Desert Res. 14, 2007
[9] A.K. Rajanvashi, Development of Safflower Petal Collector, Nimbkar Agricultural Research Institute (NARI)

[10] R.H. Perry, D.W. Green, Perry's Chemical Engineers' Handbook, McGraw-Hill. ISBN: 0071422943, 9780071422949, 2008

[11] P.F. Bleier, Fan Handbook, Selection, Application and Design, McGraw- Hill, ISBN 0-07-005933-0, 1997

[12] F.M. White, Fluid Mechanics, McGraw-Hill, ISBN: 0073529346, 9780073529349, 2009

[13] T.A. Suleimanov, Phenolic compounds from Carthamus tinctorius, Chemistry of natural compounds, Vol. 40, 2004 